\title{
BT kılavuzluğunda transtorasik kesici iğne akciğer biyopsisi: tanısal etkinliği ve komplikasyon oranları
}

\section{CT-guided transthoracic core needle lung biopsy: diagnostic efficacy and complication rates}

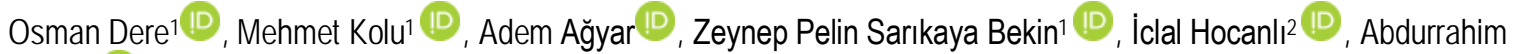 \\ Dusak $^{1}$ \\ 1 Harran Üniversitesi Tıp Fakültesi Radyoloji Anabilim Dalı, Şanlıurfa \\ 2 Harran Üniversitesi Tıp Fakültesi, Göğüs Hastalıkları Anabilim Dalı, Şanlıurfa, Türkiye
}

\section{Öz.}

Amaç: Bu çalışmanın amacı bilgisayarlı tomografi (BT) kılavuzluğunda transtorasik akciğer kesici iğne biyopsilerinin tanısal etkinliğini ve komplikasyon oranlarını göstermektir.

Materyal ve metod: Çalışmaya BT kılavuzluğunda transtorasik kesici iğne akciğer biyopsisi yapılan 50 hastanın 50 akciğer lezyonu dahil edildi. Hastaların $31^{\prime}$ i erkek 19 ' u kadın ve yaş ortalaması 58,16 idi. Akciğer lezyonlarının yerleşimi, boyutu, morfolojik yapısı ve geçilen akciğer parankim uzunluğu, histopatolojik sonuçlar ve komplikasyon oranları elde edildi.

Bulgular: Biyopsi sonucu 50 lezyonun 46 tanesinde tanısal sonuç elde edildi. Dört hastada alınan biyopsi materyali yetersiz bulundu. Tanısal sonuç elde edilen 46 lezyonun 30 ' unda malign bulgular, 16 sında benign bulgular elde edildi. İşlem sırasında ve sonrasında üç hastada pnömotoraks, dört hastada hemoraji ve üç hastada pnömotoraks ve hemoraji birlikte gelişti.

Sonuç: BT kılavuzluğunda transtorasik kesici iğne akciğer biyopsisi güvenli ve akciğer lezyonlarının tanısında etkin bir yöntemdir.

Anahtar Kelimeler: Bilgisayarlı tomografi, Akciğer lezyonu, Akciğer biyopsisi

Abstract

Background: The aim of this study was to investigate the diagnostic efficacy and complication rates of computed tomography (CT) guided core needle transthoracic lung biopsies.

Methods: 50 lung lesions of 50 patients who underwent CT guided transthoracic core needle lung biopsy were included in the study. Thirty-one patients were male and 19 were female and the mean age was 58,16 . The location, size, morphological structure of lung lesion and length of traversing lung parenchyma, histopathological results and complication rates were obtained.

Results: Diagnostic results were obtained in 46 of 50 lesions. Biopsy material was inadequate in four patients. Of the 46 lesions with diagnostic results, 30 had malignant and 16 had benign findings. Pneumothorax in three patients, hemorrhage in four patients and both pneumothorax and hemorrhage in three patients evolved during and after the procedure.

Conclusion: CT guided transthoracic core needle lung biopsy is a safe and effective method for the diagnosis of lung lesions.

Key Words: Computed tomography, Lung lesion, Lung biopsy

\section{Sorumlu Yazar I \\ Corresponding Author}

\section{Dr. Osman Dere}

Harran Üniversitesi Tıp Fakültesi Radyoloji Anabilim Dalı, Şanlıurfa

Tel: +90 5445532951

E-mail: drderectf@hotmail.com

Geliş tarihi / Received: 27.06.2019

Kabul tarihi / Accepted: 30.07.2019

DOI: 10.35440/hutfd.583179 


\section{Giriş}

Görüntüleme yöntemlerinin gelişmesiyle birlikte tanı konulan akciğer lezyonlarının sayısında belirgin artış izlenmiştir. Rezeke edilen pulmoner noduler lezyonların yarısından fazlasının malign olduğu bildirilmiş olup hızlı ve etkili tanı konulması önem kazanmıştır (1). Bilgisayarlı tomografi (BT) kılavuzluğunda iğne biyopsisi doku örneği alınmasında ve patolojik tanının elde edilmesinde önemli yer tutmaktadır (2). Bu yöntemle lezyondan sitolojik ve/veya histopatolojik örnek alınabildiği gibi serolojik-bakteriyolojik örnekleme de yapılabilmektedir. Yöntem daha çok periferik lezyonlar için tercih edilmekle beraber gerektiği hallerde santral ve mediastinal lezyonlarda da başarılı bir şekilde kullanılabilmektedir (3). İşlemin komplikasyonları arasında pnömotoraks ilk sırada yer almakla beraber hemoraji, hava embolisi ve nadir de olsa tümör ekilimi görülebilmektedir (4). Biz de bu çalışmada BT kılavuzluğunda transtorasik kesici iğne akciğer biyopsisinin tanı etkinliğini ve işlem sırasında oluşan komplikasyon oranlarını göstermeyi amaçladık.

\section{Materyal ve Metod Hasta seçimi}

Çalışma için Harran Üniversitesi Tıp Fakültesi Etik Kurul onayı alındı. Çalışmaya katılan hastalara hasta onam formu imzalatıldı. Mart 2018 ile Mayıs 2019 tarihleri arasında BT kılavuzluğunda transtorasik kesici iğne akciğer biyopsisi yapılan hastalar retrospektif olarak incelendi. Hastaların yaş ve cinsiyet gibi demografik özellikleri elde edildi. Hastaların toraks BT görüntülerinde lezyonların boyutu, yerleşimi, morfolojik yapısı, biyopsi işlemi sırasında geçilen akciğer parankim uzunluğu ile amfizem ve bronşektazi gibi komplikasyon oranını arttırabilecek patolojilerin varlığı kaydedildi. Alınan materyallerin histopatolojik sonuçları ve işlem sırasında ve sonrasında gelişen komplikasyonlar not edildi. Belirtilen tarih aralığındaki 50 hasta çalışmaya dahil edildi. Çalışmaya dahil edilen hastaların \%62'si ( $n=31$ ) erkek iken \%38'i ( $n=19)$ kadın cinsiyetteydi. Hastaların ortalama yaşı $58,16 \pm 16,21$ yıl (min-max,23-87) idi

\section{Biyopsi işlemi}

Hasta ve hasta yakınlarına işlemin gerekliliği, etkinliği ve komplikasyonları hakkında ayrıntılı açıklama yapılarak işlem için aydınlatılmış onam formu imzalatıldı. Tüm hastaların protrombin zamanı (PT), aktive parsiyel tromboplastin zamanı (aPTT), uluslararası normalleştirimiş oran (INR) ve trombosit değerleri gibi koagülasyon faktörleri normal sınırlardaydı. İşlem öncesi hastaların BT ve pozitron emisyon tomografisi (PET) BT leri incelendi. Tüm biyopsi işlemleri 64 dedektörlü General Electric Revolution (GE Medical Systems, Milwaukee, Wis, USA) BT cihazı kılavuzluğunda ve 17 gauge (G) 10,5 cm uzunluğunda koaksiyel iğne ve $18 \mathrm{G} 15 \mathrm{~cm}$ uzunluğunda yarı otomatik kesici iğne (Geotek medikal ve sağılı hizmetleri, Ankara, Türkiye) kullanılarak gerçekleştirildi. Hastalar lezyonun yerine göre supin, prone ve lateral dekübit olarak yatıııldı. İ̧leme başlarken hastanın alacağı radyasyon miktarını azaltmak için sadece lezyonun bulunduğu alana yönelik $2,5 \mathrm{~mm}$ kesit kalınlığında görüntüler alındı. İğne giriş yerini belirlemek için metal markerlar kullanıldı. Giriş yeri belirlendikten sonra biyopsi yapılacak alan povidon iyot ile temizlenip steril şartlar altında 5-10 cc \%2' lik prilokain (Pricalest, IncPharma, İstanbul, Türkiye) ile lokal anestezi uygulandı. Ciltten plevraya ve lezyona kadar olan mesafe ölçüldü. Koaksiyel iğne plevra komşuluğuna dek ilerletilerek kontrol görüntüler alındı. Uygun trase elde edildikten sonra plevra hızlı bir şekilde geçilerek iğne lezyona kadar ilerletildi (Şekil 1,2). Koaksiyel iğnenin lezyonda olduğu kontrol görüntülerle teyit edildikten sonra iç stilesi çıkarıldı. Bu esnada hava embolisi riskini azaltmak için iğnenin açık ucu parmakla kapatıldı. Örnek haznesi ve doku içinde ilerleme mesafesi $1 \mathrm{~cm}$ ve $2 \mathrm{~cm}$ olarak ayarlanabilen yarı otomatik kesici biyopsi iğnesinin kurulumu lezyonun boyutuna göre yapıldı. Tetik kısmı geriye çekilmiş olan kesici biyopsi iğnesi koaksiyel iğne içinden lezyon bölgesine kadar ilerletildi. Tetiğe sonuna kadar basarak ateşleme işlemi yapıldı ve lezyondan 2-3 örnek alındı. Yeterli materyal elde edildikten sonra kesici biyopsi iğnesi çıkarılarak bu alan steril gazlı bezle kapatıldı. Alınan biyopsi materyalleri \%10'luk formol içeren kap içerisinde patoloji laboratuvarına gönderildi. İşlem sonrası tüm hastalara olası komplikasyonları saptayabilmek için kontrol toraks BT çekildi. Komplikasyon gelişmeyen hastalar 2 saat gözlem altında tutuldu. Pnömotoraks gelişen hastalara nazal oksijen tedavisi başlanarak aralıklı kontrol akciğer grafileri ile takip edildi.

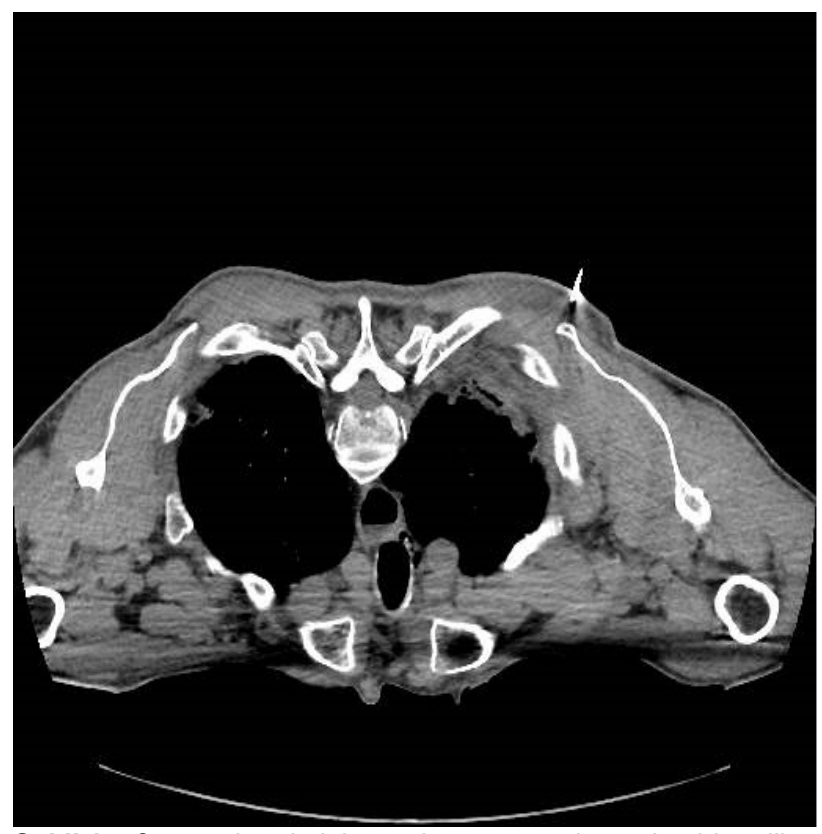

Şekil 1. 72 yaşında erkek hastada prone pozisyonda elde edilen aksiyel BT görüntüsünde sağda göğüs duvarında koaksiyel iğnenin ucu görünüyor. 


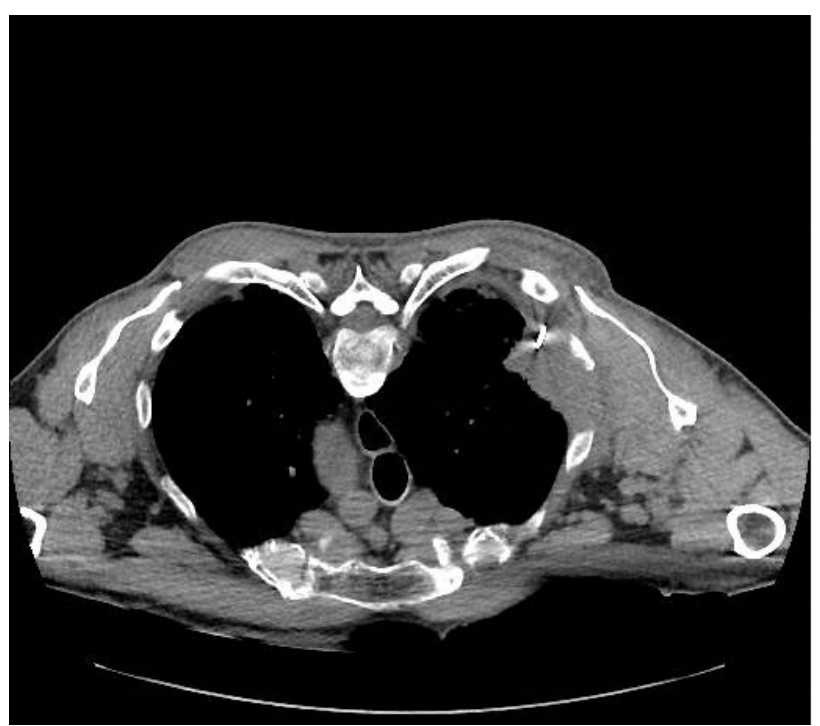

Şekil 2. Aynı hastanın sağ akciğer üst lob posterior segmentindeki kitle içerisine uzanım gösteren koaksiyel iğne. Patoloji sonucu adenokarsinom olarak saptandı.

\section{Bulgular}

Çalışmaya dahil edilen 50 hastanın 50 lezyonuna BT kılavuzluğunda transtorasik kesici iğne biyopsi işlemi yapıldı. Lezyonların 27 si sağ akciğer yerleşimliyken 23 ü sol akciğerdeydi. 10 hastanın santral, 40 hastanın periferik yerleşimli akciğer lezyonu vardı. Lezyonların 40 tanesi solid, yedi tanesi nekrotik karakterde olup iki tanesi konsolidasyon tarzında ve bir tanesinde kaba kalsifikasyonlar izlendi. Lezyonların ortalama boyutu 51,52 $\pm 33,6$ mm (min-max,9148) idi. İşlem sırasında 17 hastada akciğer parankimi geçilmiş olup, geçilen parankim uzunluğu ortalama 23,4 $\pm 10,6$ mm (min-max,10-50) olarak ölçülmüştür. Biyopsi işlemi yapılan hastaların dört tanesinde amfizem izlenmiş olup bir hastada bronşektazik değişiklikler saptanmıştır. İşlem sonunda elde edilen kontrol toraks BT incelemelerde, dört hastada lezyon çevresinde ve iğne trasesinde kendini sınırlayan hemoraji, iki hastada genişliği iki $\mathrm{cm}$ ' yi geçmeyen minimal düzeyde pnömotoraks, bir hastada genişliği dört cm 'yi geçen ileri düzeyde pnömotoraks ve eşlik eden hemotoraks, bir hastada minimal düzeyde hemoraji ve orta düzeyde pnömotoraks ve iki hastada minimal düzeyde pnömotoraks ve kendini sınırlayan minimal hemoraji saptandı. Patoloji sonucu 46 hastada pozitif çıkarken dört hastada alınan materyal yetersiz bulundu. Yetersiz materyal elde edilen bir hastanın kontrol görüntülerinde lezyon boyutlarında regresyon izlenmesi üzerine yeniden biyopsi işlemi yapılmadı. Diğer üç hastaya yeniden biyopsi önerildi. Patoloji sonucu pozitif çıkan 46 hastanın 30 'unda malignite lehine bulgular, 16 tanesinde benign bulgular saptandı. Malignite bulgusu olan 30 hastanın 24 'ünde spesifik tanı elde edilirken 16 benign lezyonun dört tanesinde spesifik tanı konulmuştur. Spesifik tanı konulan malignitelerin 13 tanesinde adenokarsinom, bir hastada küçük hücreli akciğer karsinomu, bir hastada lenfoma, bir hastada timoma, beş hastada squamöz hücreli karsinom ve üç hastada metastaz saptanmıştır. Ayrıca spesifik benign bulgular olarak üç hastada granülomatöz inflamasyon ve bir hastada kondroid hamartom tanısı elde edilmiştir.

\section{Tartışma}

Bu retrospektif çalışmada BT kılavuzluğunda transtorasik kesici iğne akciğer biyopsisinin tanı etkinliği \%92 olarak bulunmuştur. Tanı konulamayan biyopsi oranları $\% 8$ olarak elde edilmiştir. Tanı konulan lezyonların $\% 60,8$ inde spesifik bir tanı elde edilmiştir. Komplikasyon oranları toplamda $\% 20$ olup hastaların \% 14' ünde hemoraji, \% 12' sinde pnömotoraks ve $\% 2$ sinde hemotoraks gelişmiştir. BT kılavuzluğunda transtorasik akciğer biyopsilerinde rutin olarak ince iğne aspirasyon biyopsisi (ïAB) ve kesici iğne biyopsisi yöntemleri kullanılmaktadır. Bizim çalışmamızda sadece koaksiyel kesici iğne biyopsisi uygulanmıştır. IIIAB' de sitolojik inceleme için aspirasyon materyali alınırken kesici iğne biyopsisinde histolojik inceleme için doku parçası alınmaktadır $(5,6)$. Gong Y ve ark.'nın (7) yaptı̆ı retrospektif çalışmada ince iğne aspirasyon ve kesici iğne biyopsisi için tanısal doğruluk oranları malign epitelyal tümörler için benzer iken, malign nonepitelyal tümörler ve benign lezyonlar için kesici iğne biyopsisinin tanısal doğruluğu daha yüksek bulunmuştur. İnce iğne aspirasyon biyopsisi ve kesici iğne biyopsisinin birlikte kullanılması ise malign kitlelerde en yüksek doğruluk oranına $(\% 95,2)$ ulaşılmasını sağlamıştır. Jae LI ve ark.'nın (8) yaptığı çalışmada 10 mm ' den küçük lezyonlar için de kesici iğne biyopsisinin etkin ve güvenilir bir yöntem olduğu gösterilmiştir. Aktaş ve ark.'nın (9) 85 hasta üzerinde yaptığı retrospektif çalışmada kesici iğne biyopsisi ile bizim çalışmamıza benzer oranda $(\% 62,8)$ spesifik tanı elde edilirken IIIAB ile hiçbir hastada spesifik tanı konulamamıştır.

İslem sırasında ve sonrasında gelişen komplikasyonlar arasında pnömotoraks ve hemoraji ilk sıralarda yer almakta ve nadiren hava embolisi ile tümör ekilimi oluşabilmektedir. Bizim hastalarımızın hiç birinde hava embolisi ve tümör ekilimi saptanmadı. Pnömotoraks riski \% 0- 61 gibi geniş bir aralıkta gelişmesine rağmen toraks tüpü intiyacı \% 3-15 hastada oluşmaktadır (10). İiAB ile kesici iğne biyopsisi kullanımında gelişen pnömotoraks oranlarında belirgin farklılık saptanmamış olmakla beraber iğne kalınlığının artışı ile pnömotoraks riskinin arttığı gözlenmiştir (11). Pnömotoraks gelişen hastalarda iğne ile aspirasyon ilk tercih edilen tedavi yöntemidir $(12,13)$. Iğne ile aspirasyonun yeterli olmadığı durumlarda standart geniş lümenli göğüs tüpü yerine hastalar için daha az ağrılı ve uygulanması kolay olan pigtail kateterlerin kullanımı yaygınlaşmaktadır (14). Bizim çalışmamızda işlem sırasında pnömotoraks gelişen hastalardan bir tanesi iğne ile aspirasyon yöntemi ile tedavi edilirken iki hastaya seldinger yöntemiyle plevral 
aralığa 6 french $(F)$ pigtail kateter (Boston Scientific, Natick, Mass, USA) takılarak perkütan pnömotoraks tedavisi yapılmış olup göğüs tüpü intiyacı oluşmamıştır (Şekil 3,4). Bu çalışmaya dahil edilen hasta sayısının göreceli olarak düşük olması ve çalışmamızın retrospektif olması olası kısıtllııkları olarak düşünülmektedir.

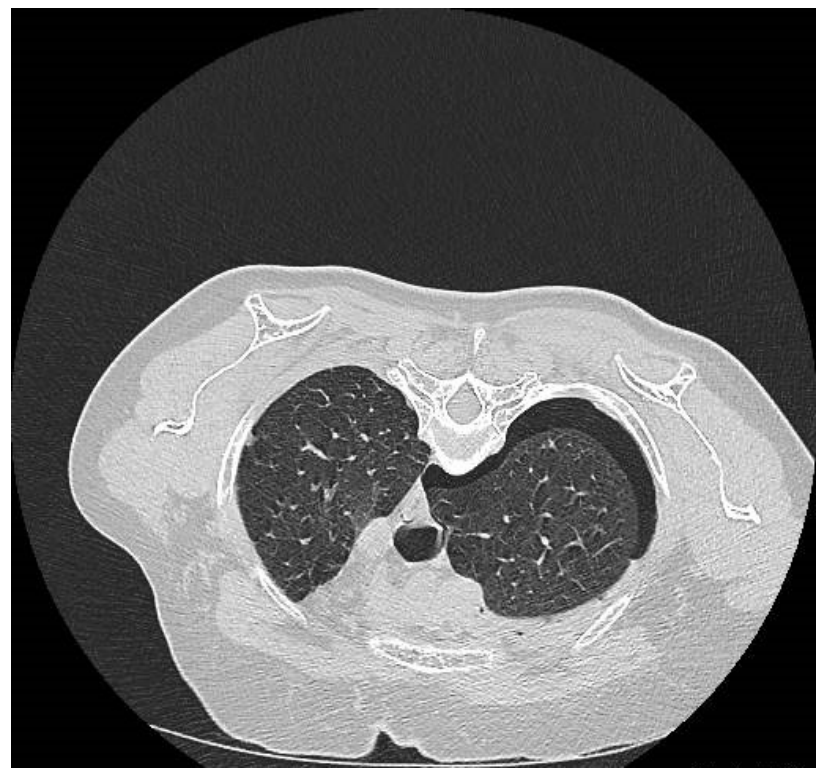

Şekil 3. 55 yaşında bayan hastada prone pozisyonda elde edilen aksiyel BT görüntüsünde sağda iatrojenik pnömotoraks

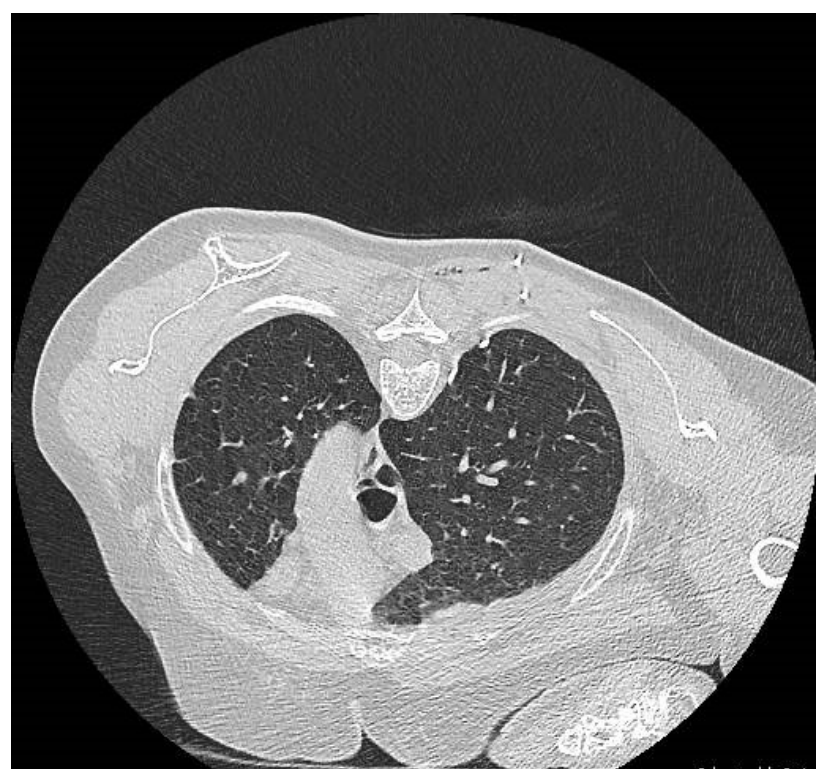

Şekil 4. Aynı hastaya BT masasında takılan pigtail kateter ile yapılan perkütan pnömotoraks tedavisi sonrası tama yakın rezorbsiyon izlenmiş̧tir.

Sonuç olarak BT kılavuzluğunda transtorasik kesici iğne akciğer biyopsisi malign ve benign akciğer lezyonlarının tanısında etkin ve güvenilir bir yöntem olup daha invazif cerrahi girişimlerin sayısını azaltmaktadır. İșlem sırasında ve sonrasında gelişen komplikasyonlar kabul edilebilir dü- zeyde olup özellikle oluşabilecek pnömotoraksın işlem sırasında tedavi edilebilmesi yöntemin uygulanabilirliğini arttırmaktadır.

\section{Kaynaklar}

1. Shah PL, Singh S, Bower M, Livni N, Padley S, Nicholson AG. The role of transbronchial fine needle aspiration in an integrated care pathway for the assessment of patients with suspected lung cancer. J Thorac Oncol 2006; 1: 324-7.

2. Zhou $Y$, Thiruvalluvan $K$, Krzeminski L, Moore WH, Xu Z, Liang Z. CT-guided robotic needle biopsy of lung nodules with respiratory motion - experimental system and preliminary test. Int J Med Robot 2013; 9: 317-30.

3. Gümüştaş $S$, Çiftçi $E$. Akciğer Kanseri Tanısında Perkütan Biyopsiler. Trd Sem 2014; 2: 354-63.

4. Yeow KM, Su IH, Pan KT, Tsay PK, Lui KW, Cheung YC, et al. Risk factors of pneumothorax and bleeding: multivariate analysis of 660 CT-guided coaxial cutting needle lung biopsies. Chest. 2004; 126(3):748-54.

5. Manhire A, Chairman CM, Clelland C, Gleeson F, Miller R, Moss $\mathrm{H}$, et al. Guidelines for radiologically guided lung biopsy. Thorax 2003; 58:920-36.

6. American Thoracic Society (ATS), European Respiratory Society (ERS). Pretreatment evaluation of non-small cell lung cancer. Am J Respir Crit Care Med 1997; 156:320-32.

7. Gong Y, Sneige N, Guo M, Hicks ME, Moran CA. Transthoracic fine needle aspiration vs concurrent core needle biopsy in diagnosis of intrathoracic lesions: a retrospective comparison of diagnostic accuracy. Am J Clin Pathol 2006; 125: 438-44.

8. Jae LI, June IH, Miyeon Y, Kwanseop L, Yul L, Hoon BS. Percutaneous core needle biopsy for small $(<10 \mathrm{~mm})$ lung nodules: accurate diagnosis and complication rates. Diagn Interv Radiol 2012; 18:527-30.

9. Aktaş AR, Gözlek E, Yılmaz Ö, Kayan M, Ünlü N, Demirtaş H, et al. CT-guided transthoracic biopsy: histopathologic results and complication rates. Diagn Interv Radiol 2015; 21:67-70.

10. Topal U, Berkman YM. Effect of needle tract bleeding on occurrence of pneumothorax after transthoracic needle biopsy. Eur J Radiol 2005; 53: 495-9

11. Min L, Xu X, Song Y, Issahar BD, Wu J, Zhang L, et al. Breathhold after forced expiration before removal of the biopsy needle decreased the rate of pneumothorax in CT-guided transthoracic lung biopsy. Eur J Radiol 2013; 82: 187-190.

12. MacDuff A, Arnold A, Harvey J. BTS Pleural Disease Guideline Group. Management of spontaneous pneumothorax: British Thoracic Society pleural disease guideline 2010. Thorax 2010; 65: 1831.

13. Kulvatunyou N, Erickson L, Vijayasekaran A, Gries L, Joseph B, Friese RF, et al. Randomized clinical trial of pigtail catheter versus chest tube in injured patients with uncomplicated traumatic pneumothorax. Br J Surg 2014; 101: 17-22.

14. Brims FJ, Maskell NA. Ambulatory treatment in The management of pneumothorax: a systematic review of the literature. Thorax 2013; 68: 664-9. 